\title{
Improvement of Sinter Productivity by Adding Return Fine on Raw Materials after Granulation Stage
}

\author{
Masaru MATSUMURA, ${ }^{1) *}$ Yasuhide YAMAGUCHI, ${ }^{1)}$ Masaki HARA, ${ }^{1)}$ Chikashi KAMIJO, ${ }^{1)}$ Takazo KAWAGUCHI ${ }^{1)}$ \\ and Youichi NAKAGAWA ${ }^{2 l}$
}

1) Corporate R\&D Laboratories, Sumitomo Metal Industries, Ltd., 16-1 Sunayama, Kamisu, Ibaraki, $314-0255$ Japan.

2) Kashima Steel Works, Sumitomo Metal Industries, Ltd., 3 Hikari, Kashima, Ibaraki, 314-0014 Japan.

(Received on July 9, 2012; accepted on September 10, 2012)

\begin{abstract}
In order to increase the permeability of the sintering bed for sinter ore productivity, RF-MEBIOS (Return Fine - Mosaic Embedding Iron Ore Sintering) process, in which return fine as dry particle is added on granulated raw materials and then they are charged into sintering machine, is proposed. In RF-MEBIOS, it is demonstrated by pot tests that productivity increases at the same moisture content in sinter mixture at charging. This productivity increase is caused by higher permeability in sinter packed bed due to two major phenomena. One is increasing the pseudo-particle size at granulation and the other is decreasing the bulk density of sinter packed bed after charging. The former is achieved by a higher moisture content in the raw materials at granulation, which has the role of decreasing small size of pseudo-particle $(-0.25$ $\mathrm{mm}$ ). The latter is achieved by higher friction in the packed bed composed of dry and wet particles compound, which has a role of decreasing bulk density. In the development of RF-MEBIOS, return fine was chosen as the dry particle because it is dry when produced by the sintering machine. The sinter productivity increases with the increase of the quantity of the return fine added after granulation stage. The effect of pseudo-particle $(-0.25 \mathrm{~mm})$ ratio and $\varepsilon$ on flame front speed were evaluated as $55 \%$ and $41 \%$ to increase of frame front speed, respectively.

Effect of RF-MEBIOS on sinter productivity is confirmed in No.3 sinter plant in Kashima Steel Works. Under the condition of constant moisture content in sinter mixture at charging, this improvement degree is proportioning to the ratio of bypass return fine which is added to granulated the other sinter materials without granulation. It means granulation at higher moisture has superiority compared to increase of fine material in bypass return fine.

Finally, RF-MEBIOS method is installed on three commercial sintering machines (Kashima, Wakayama, and Kokura) belonging Sumitomo Metals. In all three sinter plants, productivity increase has been confirmed. Therefore, introducing RF-MEBIOS has been demonstrated to cause a universal improvement of sinter productivity.
\end{abstract}

KEY WORDS: iron ore; sintering process; productivity; return fine (RF); granulation; pseudo-particle; sinter packed bed; bulk density; MEBIOS; RF-MEBIOS.

\section{Introduction}

Sinter productivity strongly depends on sinter permeability in sinter packed bed due to increase of air flow rate in it. Furthermore, high sinter permeability is achieved by large pseudo-particle which is sinter raw materials after granulation, and high void ratio of sinter packed bed represented as Ergun Formula.

In fact, charging mini-pellet, ${ }^{1,2}$ which is large particle as pseudo-particles in sinter process has a roll of increasing permeability. And for increasing pseudo-particle size it is effective to utilize pre-granulation process. ${ }^{3)}$ Pre-granulation process has the two and more granulation routes and after granulation in each route they are gathered and charged into sinter machine. This process has been applied in lots of

* Corresponding author: E-mail: matsumura.7fh.masaru@jp.nssmc.com DOI: http://dx.doi.org/10.2355/isijinternational.53.34
Japanese sinter plant in various styles ${ }^{4-6)}$ based on fundamental study as duplex mini-pellet. ${ }^{7)}$ When introducing the process, granulation device generally called "mixer" has also examined for determination of essential mechanical parameters, for example angle size and rotation speed. ${ }^{8)}$

On the other hand, void ratio of sinter packed bed is the other capital parameter for high permeability has been mainly achieved by charging apparatus for loose packing. However, additional to void ratio at charging, maintaining high void rate at sintering is necessary. One major countermeasure is decreasing moisture content by drying after charging in order to decrease amount of moisture condensation. ${ }^{13)}$ Moisture affects decreasing permeability at sintering otherwise it is indispensable as binder at granulation.

Recently, as controlling the bed structure technique for high permeability MEBIOS (Mosaic Embedding Iron Ore Sintering) ${ }^{12)}$ was proposed. 
The schematic view of the sintering bed structure of the MEBIOS method is shown in Fig. 1. The purpose of the MEBIOS method is making a high density but high permeability packed bed by setting denser parts and loser ones in the same packed bed. For example, high-density large green balls, with a diameter of 5 to $15 \mathrm{~mm}$, are placed in the packed bed to make lower density parts around the balls by a "wall effect" so that the permeability of the packed bed increases. It was confirmed that MEBIOS had also role of keeping high void ratio at sintering because during sintering large dense particles maintain the shape but partially aggregate with surrounded loose packed parts in sinter packed bed. ${ }^{14,15)}$

The application of MEBIOS with a low price capital investment has to be developed for product competitiveness. Finally, it has been confirmed that even small dry particle charged into the sinter packed bed has a similar effect on controlling the bed structure due to friction between dry particle and wet particle. In addition, the moisture content can be controlled at granulation and at charge into sintering bed individually, which has the effect of improving granulation. For a commercial sinter plant, return fine is used as the dry particle by bypassing the mixing and granulating route. So, this process is named "RF-MEBIOS (Return Fine - Mosaic Embedding Iron Ore Sintering)". Utilization of return fine as the dry particle functions by eliminating the drying process because return fine is utilized as raw materials soon after it is discharged from sintering machine.

In this report, from the view point of bulk density in sinter packed bed and pseudo-particle size after mixing and granulation, permeability improvement techniques based on RFMEBIOS were studied fundamentally by pot test. After that, it has been applied in three sinter plants in SMI (Kashima, Wakayama, Kokura) and productivity has been improved in each sinter plant. RF-MEBIOS is expected to be useful for not only improving sinter productivity but also countermeasure for recent increase in the amount of fine ore, such as Brazilian concentrated ultra fine. ${ }^{3)}$

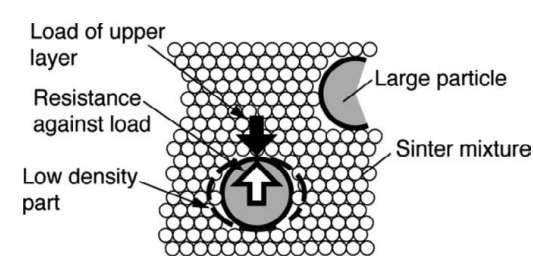

Fig. 1. Denser parts and loser ones in the same packed bed of MEBIOS. ${ }^{12)}$

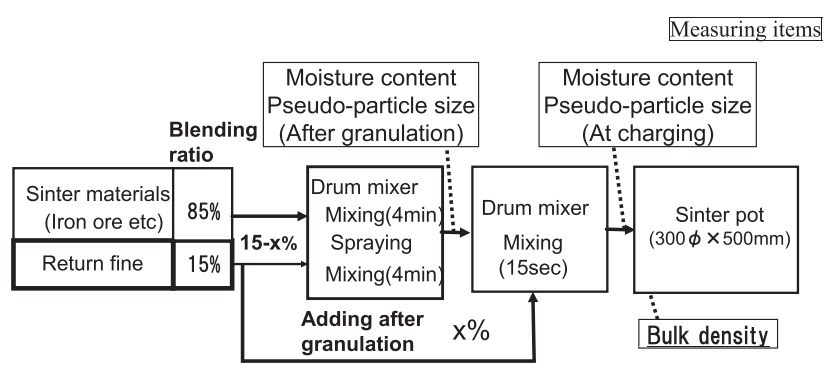

Fig. 2. Experimental flow of pot test $(300 \phi)$.

\section{Sinter Pot Examination}

\subsection{Experimental}

Figure 2 shows the experimental flow of the pot test. At first, 85 mass $\%$ of total raw materials, which were several kinds of fine ore, serpentine, limestone and 15 mass $\%$ of return fines were prepared. (Blending condition in detail is shown in Table 1). Then the raw materials except some part of the return fines (X mass $\%$ to sinter mixture) were mixed in a drum type mixer (diameter : $600 \mathrm{~mm}$, length : $800 \mathrm{~mm}$ ) for $4 \mathrm{~min}$, and a certain amount of water was sprayed and mixed again for $4 \mathrm{~min}$. The mixing after water spraying causes granulation. Then the return fine ( $\mathrm{X}$ mass\%) was added into the granulated sinter raw materials and mixed in the drum type mixer for 15 seconds. After that, they were charged into a sinter pot, which has a diameter of $300 \mathrm{~mm}$ and height of $500 \mathrm{~mm}$, to compose the packed bed. Before charging it, hearth materials which were $10-15 \mathrm{~mm}$ of sinter products were charged into the sinter pot. $\mathrm{X}$ value, which is the proportion of the return fine added after granulation stage, was varied in 5\% increments from $0 \%$ to $15 \%$. In this paper, the return fine added after granulation stage is named "bypass return fine". The moisture content was measured after granulation and at charging. And the experimental condition of the moisture content at charging was constant

Table 1. Blending condition.

\begin{tabular}{|c|c|c|c|c|c|c|c|}
\hline Route & Raw materials & \multicolumn{4}{|c|}{ Series 1} & \multicolumn{2}{|c|}{ Series 2} \\
\hline \multirow{12}{*}{$\begin{array}{c}\text { Ordinary } \\
\text { Route }\end{array}$} & Iron ore $\mathrm{R}$ & 8.5 & 8.5 & 8.5 & 8.5 & 8.5 & 8.5 \\
\hline & Iron ore $\mathrm{Y}$ & 19.1 & 19.1 & 19.1 & 19.1 & 19.1 & 19.1 \\
\hline & Iron ore $\mathrm{H}$ & 13.2 & 13.2 & 13.2 & 13.2 & 13.2 & 13.2 \\
\hline & Iron ore $\mathrm{C}$ & 8.5 & 8.5 & 8.5 & 8.5 & 8.5 & 8.5 \\
\hline & Iron ore $\mathrm{W}$ & 21.3 & 21.3 & 21.3 & 21.3 & 21.3 & 21.3 \\
\hline & Serpentine & 2.1 & 2.1 & 2.1 & 2.1 & 2.1 & 2.1 \\
\hline & Lime stone & 12.3 & 12.3 & 12.3 & 12.3 & 12.3 & 12.3 \\
\hline & Return fine & $\underline{15}$ & $\underline{10}$ & $\underline{5}$ & $\underline{0}$ & - & - \\
\hline & Return fine $(+1 \mathrm{~mm})$ & - & - & - & - & - & $\underline{7.7}$ \\
\hline & Return fine $(-1 \mathrm{~mm})$ & - & - & - & - & $\underline{7.3}$ & - \\
\hline & Sub Total & 100 & 95 & 90 & 85 & 92.3 & 92.7 \\
\hline & Coke breeze $(-5 \mathrm{~mm})$ & {$[4.5]$} & {$[4.5]$} & [4.5] & {$[4.5]$} & {$[4.5]$} & [4.5] \\
\hline \multirow{4}{*}{$\frac{\frac{\text { Added after }}{\text { granulation }}}{\underline{\text { stage }}}$} & Return fine & $\underline{\mathbf{0}}$ & $\underline{5}$ & $\underline{10}$ & $\underline{15}$ & - & - \\
\hline & Return fine $(+1 \mathrm{~mm})$ & - & - & - & - & $\underline{7.7}$ & - \\
\hline & Return fine $(-1 \mathrm{~mm})$ & - & - & - & - & - & $\underline{7.3}$ \\
\hline & Sub Total & $\underline{\mathbf{0}}$ & $\underline{5}$ & $\underline{10}$ & $\underline{15}$ & $\underline{7.7}$ & $\underline{7.3}$ \\
\hline \multicolumn{2}{|r|}{ Total } & 100 & 100 & 100 & 100 & 100 & 100 \\
\hline & Coke breeze $(-5 \mathrm{~mm})$ & {$[4.5]$} & {$[4.5]$} & [4.5] & {$[4.5]$} & {$[4.5]$} & [4.5] \\
\hline
\end{tabular}
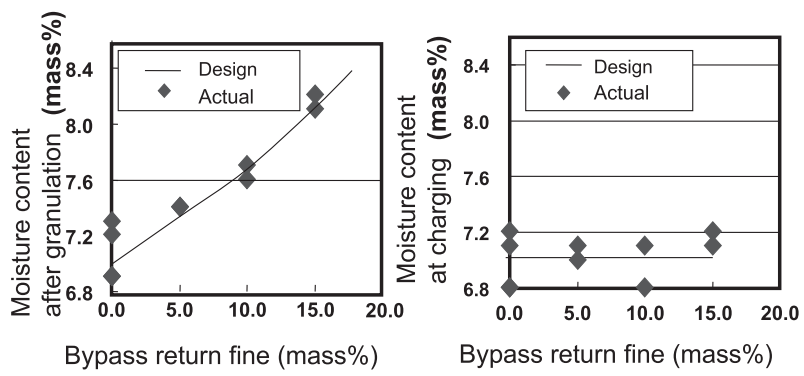

Fig. 3. Moisture content in sinter raw materials after granulation and at charging. 
(7.0\%). Thus with an increasing $\mathrm{X}$ value, the moisture content after granulation increased.

Figure 3 shows the relation between the bypass return fine ratio and the moisture content after granulation and at charging for designed and actual values. Actual values were matched with the designed one.

Pseudo-particle size was also measured both after granulation and at charging. The measuring method was mechanical sieving with several size of meshes for 15 seconds without tapping after dry treatment for $2 \mathrm{~h}$ under 105 degree $\mathrm{C}$. After charging into sintering pot, bulk density was calculated by dividing material weight with inner volume of pot.

Blending condition is shown in Table 1. The purpose of Series 1 and Series 2 is to investigate for the bypass return fine ratio and size, respectively. 5 kinds of major iron ore fines in Japan were used. The coke breeze blending ratio was $4.5 \%$ to the total raw materials. In Series 2, the blending ratio of return fine $(+1 \mathrm{~mm})$ and return fine $(-1 \mathrm{~mm})$, which were $7.7 \%$ and $7.3 \%$ respectively, corresponds to the size distribution of return fine shown in Fig. 4, in which $-1 \mathrm{~mm}$ ratio is $49 \%$.

Sintering was performed under constant pressure drop of $10.3 \mathrm{kPa}$ of sinter packed bed, after igniting by LPG burner for 1 min under $5.2 \mathrm{kPa}$. Pressure was measured in wind box and was controlled by opening degree of dumper at main exhaust pipe set between the wind box and fan. Sintering end was determined at 3 min later from BTP, which is the timing at maximum temperature of exhaust gas measured at center position in wind box.

Then sinter cake was discharged from pot and was dropped of $2 \mathrm{~m}$ height for 4 times. After drop, it was sieved by $5 \mathrm{~mm}$. Upper size was defined sinter product plus hearth materials $(2.0 \mathrm{~kg})$.

The weight of sinter product was determined as weight of upper size $-2.0 \mathrm{~kg}$. Then yield was defined as the weight of sinter product divided by weight of sinter cake $-2.0 \mathrm{~kg}$. Sintering time was defined by time from starting ignition to BTP and sinter productivity was defined as weight of sinter product divided by sintering time and by area of the sinter pot. Frame front speed was defined as height of sinter packed bed at charging divided by the passing time from starting igniting to FFP, which is the timing at starting increasing temperature of exhaust gas. Bulk density was calculated as weight of sinter raw materials in pot at charging divided by inner volume of the sinter pot except the zone occupied by hearth materials.

\subsection{Results}

Figures 5 through 7 show the results for productivity, FFS, and yield, respectively.

With the increasing ratio of bypass return fine, productivity and FFS increased. And bypassing large particle (+1

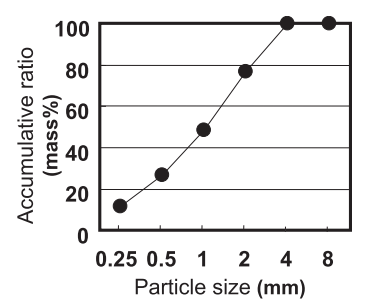

Fig. 4. Size distribution of return fine. $\mathrm{mm})$ was better for them compared with bypassing small particle $(-1 \mathrm{~mm})$.

In the case of $15 \%$ return fines bypass, the pot yield was decreased. Excess high FFS caused a decrease of yield.

Results of the bulk density and pseudo-particle size $(-0.25$ $\mathrm{mm}$ ) ratio is shown in Fig. 8 .

With decreasing ratio of bypass return fine, the bulk density and pseudo-particle size $(-0.25 \mathrm{~mm})$ ratio after dry treatment decreased. And the case of large particle $(+1 \mathrm{~mm})$ bypass shows a slightly smaller values for them compared with the case of small particle $(-1 \mathrm{~mm})$ bypass.

To summarize the results, adding dry return fine to gran-

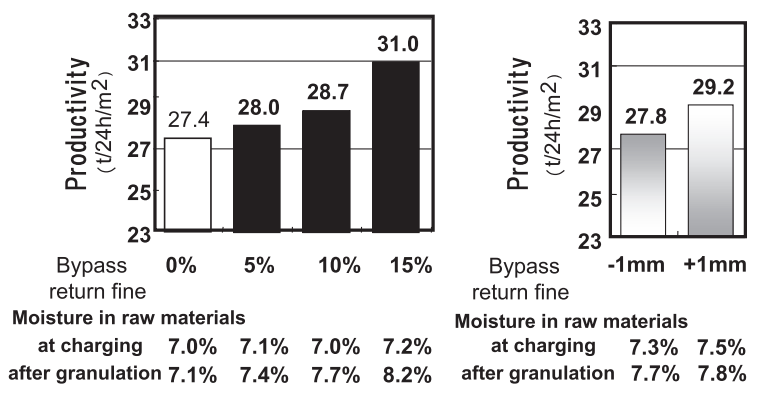

Fig. 5. Improvement of productivity by return fine addition after granulation stage.

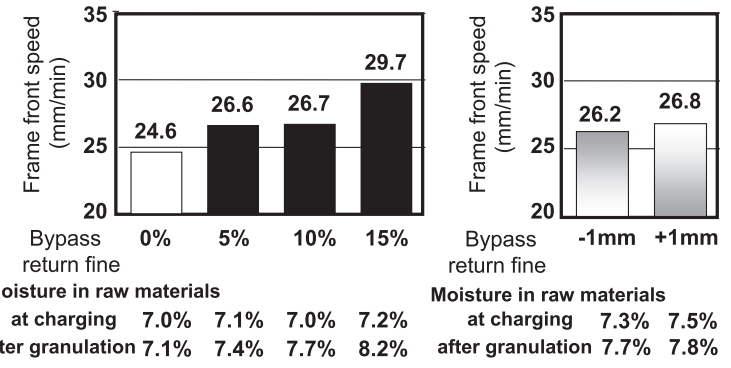

Fig. 6. Effect of return fine added after granulation stage on frame front speed.

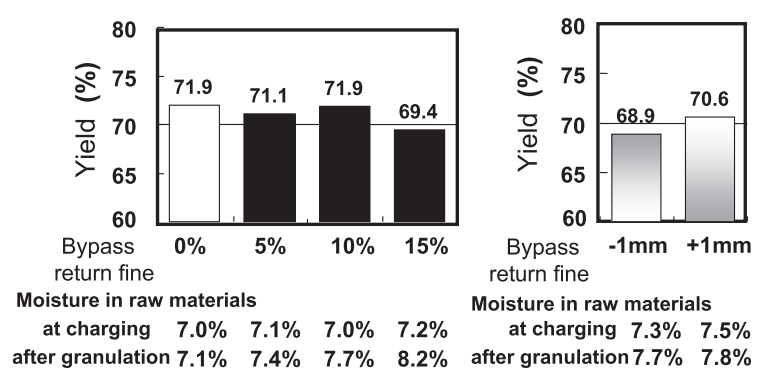

Fig. 7. Influence of return fine added after granulation stage on yield.
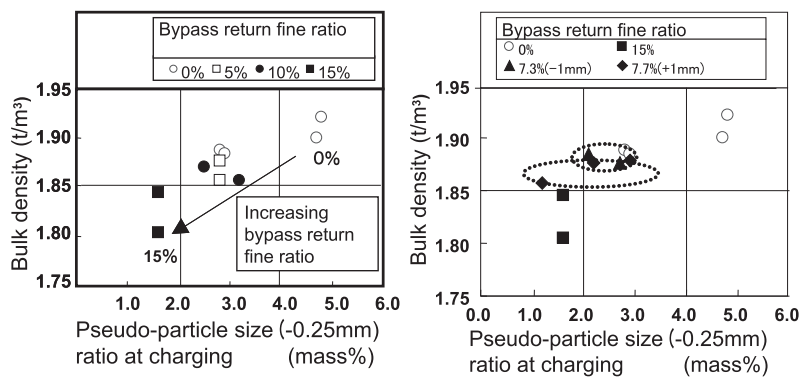

Fig. 8. Effect of yield by return fine added after granulation stage on bulk density and pseudo-particle size. 
ulated raw materials under the condition at which moisture content after adding is equal, pseudo-particle size $(-0.25$ $\mathrm{mm}$ ) ratio decreases due to higher moisture content in raw materials after granulation.

In addition, the bulk density decreases when the mixture includes dry particles. It is assumed that friction between particles contributes to low bulk density.

\subsection{Discussion}

Generally, FFS depends on heat transfer from upper zone to lower zone in sinter packed bed, as frame front means starting carbon burning. And two kinds of heat transfer are considered in sintering process. One is forced-convection heat transfer due to gas flow downstream. The other is conductive heat transfer directly between particles. In addition, the former depends on the permeability of the sinter packed bed and moisture content of materials in it. And the permeability of the pack bed is a function of pore ratio and particle size as shown in the Ergun Equation.

In fact, from Figs. 6 and 8, high FFS cases, which has condition of high bypass return fine ratio show low bulk density and pseudo-particle size $(-0.25 \mathrm{~mm})$ ratio.

Bulk density definitely corresponds to void ratio $(\varepsilon)$ because blending condition is equal in all cases, which means average apparent density is equal. Void ratio $(\varepsilon)$ is calculated from bulk density and mean apparent density. And pseudo-particle size $(-0.25 \mathrm{~mm})$ ratio is adopted parameter as particle size in sintering process, because in previous study, ${ }^{16)}$ strong relation between pseudo-particle size $(-0.25 \mathrm{~mm})$ ratio and FFS has been observed. Then, FFS is represented as formula (a').

FFS $(\mathrm{mm} / \mathrm{min})=\mathrm{a} \cdot(1-\mathrm{b} \cdot($ Pseudo-particle size $(-0.25 \mathrm{~mm})$ ratio $(\%)) / 100) \cdot(1-\mathrm{c} \cdot($ moisture content at charging $(\%) / 100)) \times\left(\varepsilon^{3} /(1-\varepsilon)\right)^{0.6}+h$.

In this formula (a'), the former term corresponding to convection heat transfer between gas and a particle, depends on pseudo-particle size $(-0.25 \mathrm{~mm})$ ratio, moisture content at charging, and pore ratio $(\varepsilon)$ and the latter term corresponding to conductive heat transfer directly between particles is constant $(h)$.

Based on previous studies ${ }^{16,17)}$ of examination for effects of FFS increase by pore ratio, pseudo-particle size, and moisture content, parameters (a to c and $h$ ) in formula (a') is determined as shown in formula (a).

FFS $(\mathrm{mm} / \mathrm{min})=86.67(1-0.247$ (Pseudo-particle size $(-0.25 \mathrm{~mm})$ ratio $(\%)) / 100) \cdot(1-3.20$ (moisture content at charging $(\%) / 100)) \times\left(\varepsilon^{3} /(1-\varepsilon)\right)^{0.6}+2.33$.

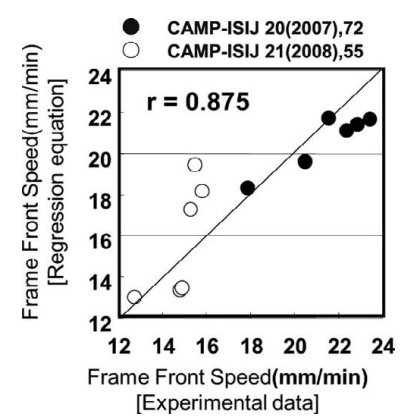

Fig. 9. Verification of regression equation.
In formula (a), pseudo-particle size $(-0.25 \mathrm{~mm})$ ratio, moisture content at charging, and $\varepsilon$ are limited as bellows. These limitation is defined based on experimental conditions of previous study. ${ }^{16,17)}$

$0.4<$ pseudo-particle size $(-0.25 \mathrm{~mm})$ ratio $(\operatorname{mass} \%)<5.6$

$5.3<$ moisture content at charging $(\operatorname{mass} \%)<8.3$

$0.32<\varepsilon(-)<0.42$

Figure 9 shows relationship between actual value and calculation value. Correlation factor of 0.875 is high, which proves formula (a) is adopted when each parameter is within limitation of experimental conditions. ${ }^{16,17)}$

Based on the formula (a), the effect of the pore ratio $(\varepsilon)$ and the pseudo-particle size $(-0.25 \mathrm{~mm})$ ratio on frame front speed are evaluated individually as broken lines in Fig. 10. Large circle in both Fig. is basic point, which is determined by substituting data of pseudo-particle size $(-0.25 \mathrm{~mm})$ ratio, moisture content at charging, and pore ratio $(\varepsilon)$ in the formula (a) when bypass return fine ratio is $0 \%$. Then the broken lines is determined as function of pore ratio $(\varepsilon)$ and the pseudo-particle size $(-0.25 \mathrm{~mm})$ ratio respectively with the other parameters are constant, based on the formula (a).

Solid line is determined by experimental results in this work and inclination of the solid line is reflected all elements concerned with frame front speed. Then ratio of inclination of broken lines to that of solid line indicates relative contribution of $\varepsilon$ and pseudo-particle size $(-0.25 \mathrm{~mm})$ ratio on frame front speed, respectively. And effect of $\varepsilon$ and pseudo-particle size $(-0.25 \mathrm{~mm})$ ratio on flame front speed were evaluated as $41 \%$ and $55 \%$ to total frame front speed increasing, respectively.

Figure 11 shows the mechanism by which the return fine added after granulation stage improves productivity, while
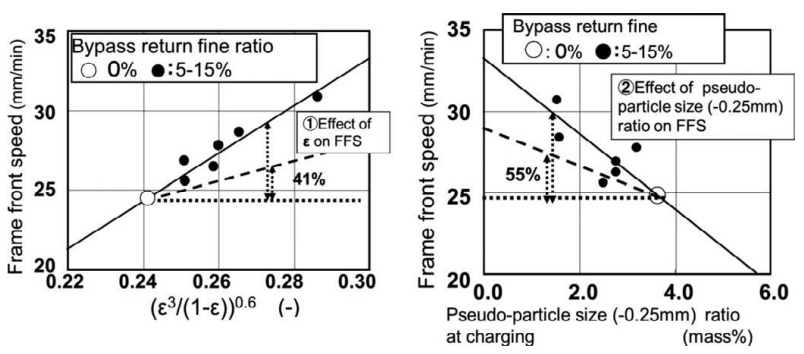

Fig. 10. Quantitative analysis for FFS increase by pore ratio and pseudo-particle size.

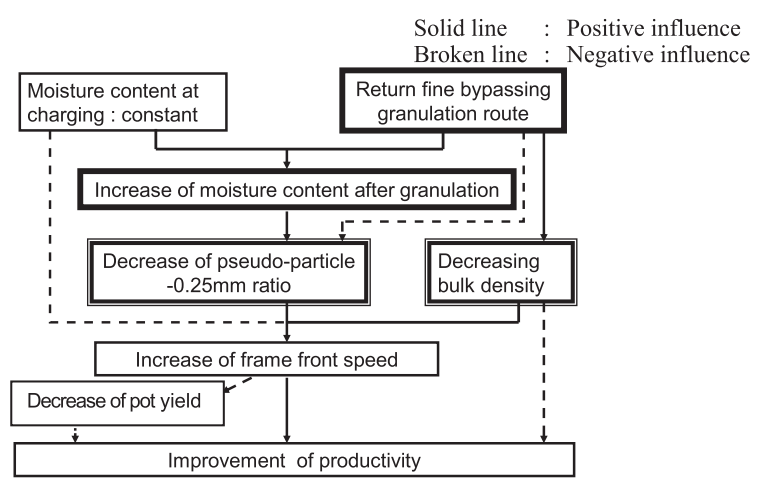

Fig. 11. Effect of RF-MEBIOS (Return fine bypassing granulation route) on improvement of productivity. 
the moisture content at charging remains constant, the bypass return fine results in an increase of moisture content after granulation. In spite of small particle $(-0.25 \mathrm{~mm})$ containing in bypass return fine, the pseudo-particle size $(-0.25$ $\mathrm{mm}$ ) ratio at charging in the sinter machine decreases with increasing the bypass return fine ratio. The reason is that higher moisture content in raw materials accelerates granulation. In addition, the bulk density is decreased by dry return fine addition into granulated wet particles. ${ }^{18)}$ Both the decrease of pseudo-particle size $(-0.25 \mathrm{~mm})$ ratio at charging and the decrease of the bulk density contributes to improving productivity.

\section{Practical Application at a Commercial Plant}

\subsection{Application at Kashima No.3 Sinter Plant}

\subsubsection{Layout of Return Fine Transportation}

The material flow is shown in Fig. 12. Transportation of return fine diverges into two routes by a divergence damper. One is to the return fine bin and the other is to the bypass return fine bin.

Then return fine at return fine bin and other sinter raw materials are mixed and granulated together with water in mixer. Return fine from bypass return fine bin are added after the mixer.

The damper position is adjusted to control the proportioning of bypass return fine. And it can separate return fines between the upper layer and the lower layer so that relative large particles can be transported to the bypass return fine bins. This divergence method is adopted because of result

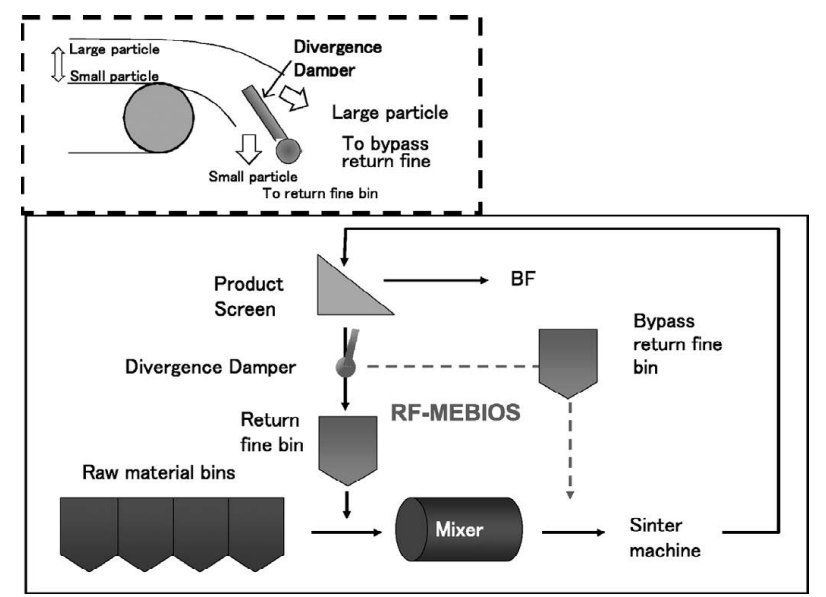

Fig. 12. Layout of return fine at commercial sinter plant.

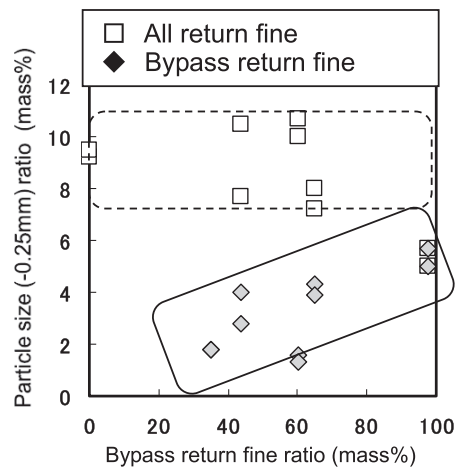

Fig. 13. Influence of bypass return fine ratio on particle size. of pot test, in which large particles bypassing mixer has superiority for productivity compared with small particles bypassing. Figure 13 shows influence of bypass return fine ratio on particle size. When the ratio is low, small particle $(-0.25 \mathrm{~mm})$ proportioning of return fine bypassing mixer is low. Thus large particle proportioning was high. And with an increase of the ratio, particle size is close to that of total return fine.

In the commercial plant test, the ratio of bypass return fine to sinter mixture were $20 \%, 14 \%, 8 \%$ with equal moisture content $(6.4-6.5 \%)$ at charging. So at high bypass return fine ratio, moisture content (\%) in sinter raw materials after granulation was high. It was $7.9 \%, 7.5 \%$ and $7.1 \%$ at each case (shown in Fig. 14).

\subsubsection{Operational Results}

Operational results are shown in Fig. 14.

High ratio of return fine bypassing granulation has an effect of high productivity $(>620 \mathrm{t} / \mathrm{h}$ ) due to high FFS.

Productivity improvement is considered from view point of raw material size distribution after granulation and at charging as well as sinter pot test.

As shown in Fig. 15, raw materials were sampled at two different points. One is sampled after granulation where bypass return fine is not joined. The other is sampled at charging into sinter machine where bypass return fine is joined.

Moisture condition in each condition

\begin{tabular}{|l|c|c|c|}
\hline Bypass return fine ratio (mass $\%$ ) & 20 & 14 & 8 \\
\hline Moisture content after granulation (mass $\%)$ & 7.9 & 7.5 & 7.1 \\
\hline Moisture content at charging (mass $\%$ ) & 6.4 & 6.5 & 6.5 \\
\hline
\end{tabular}

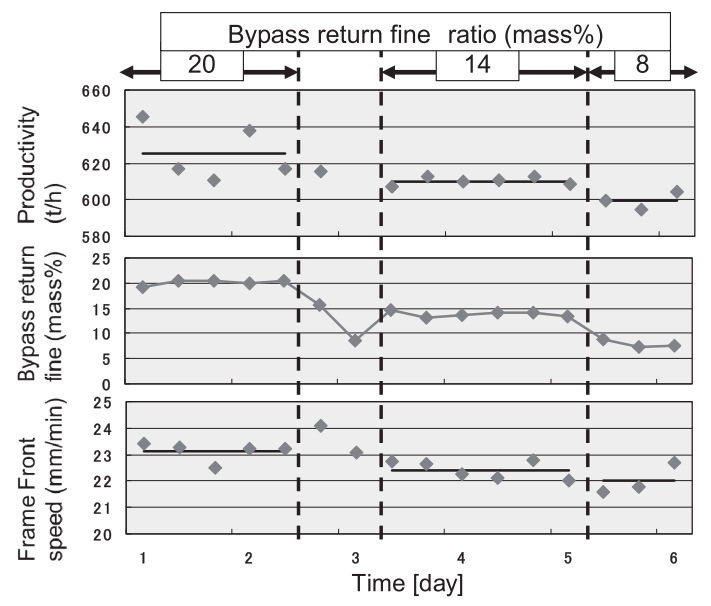

Fig. 14. Operational performances at varying bypass return fine ratio.

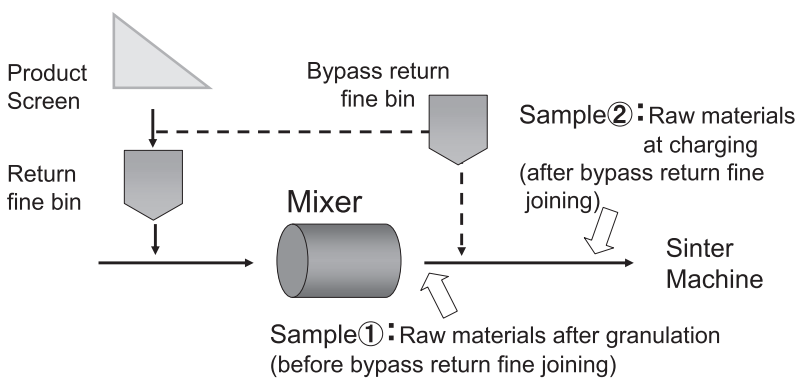

Fig. 15. Raw material sampling points for investigating size distribution. 
Figure 16 shows effect of moisture content after granulation on GI $(-0.25 \mathrm{~mm})$. And GI $(-0.25 \mathrm{~mm})$ is defined as formula (b).

The index means granulating ratio for $-0.25 \mathrm{~mm}$ diameter particles. A $(-0.25 \mathrm{~mm})$ and $\mathrm{B}(-0.25 \mathrm{~mm})$ corresponds to real particle and pseudo-particle respectively. B $(-0.25 \mathrm{~mm})$ was measured by sieving for 15 seconds without tapping after drying for $2 \mathrm{~h}$ under 105 degree $\mathrm{C}$. After that $\mathrm{A}(-0.25$ $\mathrm{mm}$ ) was measured by sieving for 5 minutes with tapping. These analyses were performed for both raw materials after granulation and at charging.

GI $(-0.25 \mathrm{~mm})(\operatorname{mass} \%)=\left(1-\frac{\mathrm{B}(-0.25 \mathrm{~mm})}{\mathrm{A}(-0.25 \mathrm{~mm})}\right) \times 100$..(b)

A $(-0.25 \mathrm{~mm}):-0.25 \mathrm{~mm}$ ratio of real particle (mass\%)

$\mathrm{B}(-0.25 \mathrm{~mm}):-0.25 \mathrm{~mm}$ ratio of pseudo-particle (mass $\%$ )

From Fig. 16, it has been confirmed that GI $(-0.25 \mathrm{~mm})$ was high at high moisture after granulation. Relation between moisture content after granulation and GI $(-0.25$ $\mathrm{mm})$ is represented as the formula shown in Fig. 16.

Figure 17 shows the effect of bypass return fine ratio on GI $(-0.25 \mathrm{~mm})$. GI $(-0.25 \mathrm{~mm})$ was high at high ratio of bypass return fine due to high moisture content (\%) after granulation. At charging into sinter machine, GI $(-0.25 \mathrm{~mm})$ decreased due to adding return fine including small particle compared to GI $(-0.25 \mathrm{~mm})$ after granulation, but GI $(-0.25$ $\mathrm{mm}$ ) kept higher in case of high bypass return fine ratio. It suggested that effect of high moisture granulation had superiority compared to adding small particle in bypass return fine without granulation.

Optimum bypass return fine ratio is key parameter for sinter plant operation. For this purpose, small particle $(-0.25$ $\mathrm{mm}$ ) ratio in sinter mixture at charging was evaluated.

Premise conditions are shown as follows.

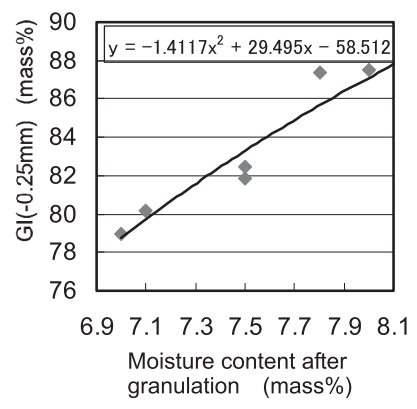

Fig. 16. Increasing GI $(-0.25)$ by high moisture content after granulation.

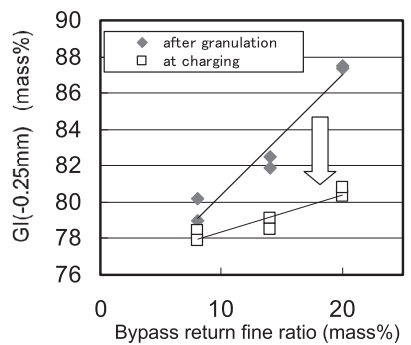

Fig. 17. Effect of bypass return fine ratio on GI $(-0.25)$.
- $-0.25 \mathrm{~mm}$ particle ratio in raw materials except return fine : $25 \%$

- Return fine ratio to sinter mixture : $20 \%$

- $-0.25 \mathrm{~mm}$ particle ratio in return fine : $4.4 \%$

- Moisture content at charging :7.0\%

Quantity of $-0.25 \mathrm{~mm}$ particle in sinter mixture at charging is considered to be addition of that of $-0.25 \mathrm{~mm}$ particle in bypass return fine to that of $-0.25 \mathrm{~mm}$ particle after granulation because $-0.25 \mathrm{~mm}$ particle in bypass return fine can not be granulated after joining to granulated materials. Then it is represented as follows.

$-0.25 \mathrm{~mm}$ ratio in sinter mixture at charging (\%)

$\times$ Sinter mixture quantity at charging $(\mathrm{t} / \mathrm{h})=-0.25 \mathrm{~mm}$ ratio in raw material after granulation $(\%) \times($ Sinter mixture quantity $(\mathrm{t} / \mathrm{h})$ - Bypass return fine quantity $(\mathrm{t} / \mathrm{h}))$ $+-0.25 \mathrm{~mm}$ ratio in bypass return fine $(\%)$

$\times$ Bypass return fine quantity $(\mathrm{t} / \mathrm{h})$......

For calculation of formula (c), sinter mixture quantity $(\mathrm{t} / \mathrm{h})$ and bypass return fine quantity $(\mathrm{t} / \mathrm{h})$ were given as operational parameters. And $-0.25 \mathrm{~mm}$ ratio in bypass return fine (\%) was defined in Fig. 13. Finally, $-0.25 \mathrm{~mm}$ ratio in raw material after granulation was calculated from GI $(-0.25 \mathrm{~mm})$ and $-0.25 \mathrm{~mm}$ particle of raw materials before granulation based on formula (b). GI ( $-0.25 \mathrm{~mm})$ was the function of only moisture content after granulation shown as the formula shown in Fig. 16. And $-0.25 \mathrm{~mm}$ particle of raw materials before granulation was calculated from 3 parameters, which were $-0.25 \mathrm{~mm}$ ratio in bypass return fine, bypass return fine ratio in sinter mixture, and $-0.25 \mathrm{~mm}$ ratio in sinter mixture.

Relation between bypass return fine ratio to sinter mixture and GI $(-0.25 \mathrm{~mm})$ and moisture content after granulation is shown in Fig. 18. And Fig. 19 shows influence of

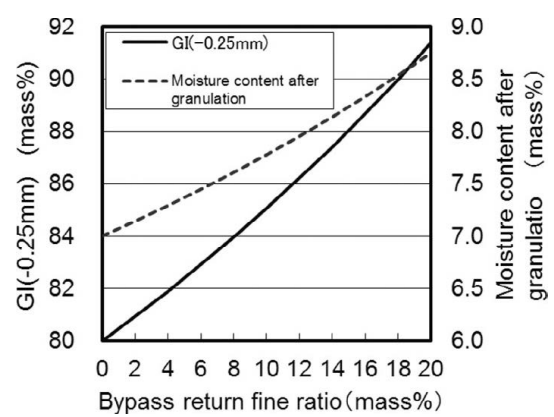

Fig. 18. GI $(-0.25)$ and Moisture content after granulation corresponding to bypass return fine ratio.

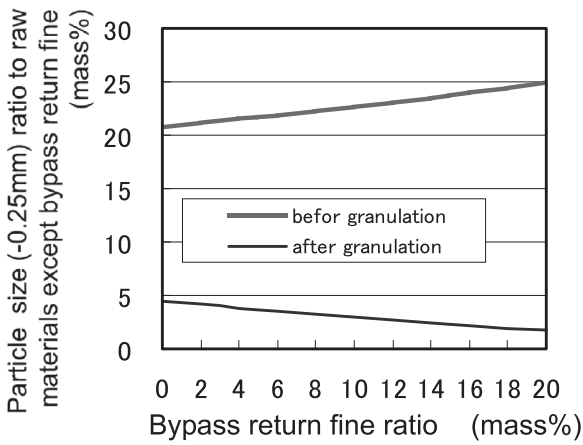

Fig. 19. Influence of bypass return fine ratio on $-0.25 \mathrm{~mm}$ particle ratio to total raw materials before and after granulation. 


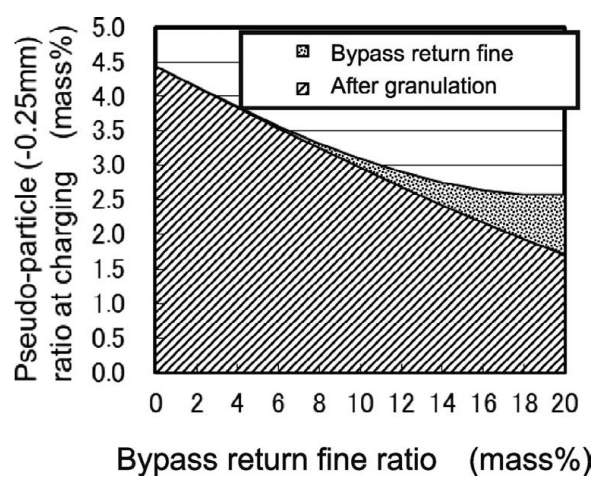

Fig. 20. Influence of bypass return fine ratio to sinter mixture to -0.25 particle ratio at charging.

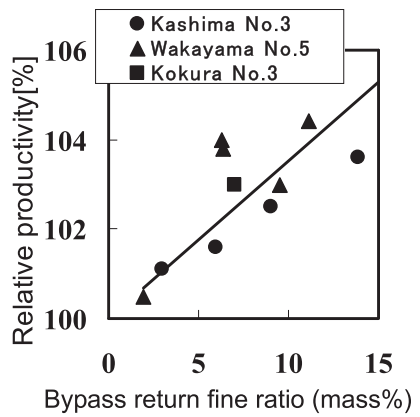

Fig. 21. Universal effect of RF-MEBIOS on productivity.

bypass return fine ratio on ratio of $-0.25 \mathrm{~mm}$ particle before and after granulation using GI $(-0.25 \mathrm{~mm})$ shown in Fig. 18 . With increasing bypass return fine ratio, the $-0.25 \mathrm{~mm}$ particle ratio after granulation decreases, in spite of increasing $-0.25 \mathrm{~mm}$ particle ratio before granulation.

Figure 20 shows influence of bypass return fine ratio to sinter mixture to $-0.25 \mathrm{~mm}$ particle ratio at charging, distinguishing those in bypass return fine and in raw materials after granulation. With increasing bypass return fine ratio, $-0.25 \mathrm{~mm}$ particle ratio at charging decreases. In this premise condition shown in previous page, it is confirmed that with increasing bypass return fine ratio to $18 \%,-0.25$ $\mathrm{mm}$ particle ratio at charging decreases.

\subsection{Evaluation at Commercial Plants}

RF-MEBIOS, which is the technique of return fine bypassing granulation, has been applied in three sinter plant. Effect of RF-MEBIOS on productivity was proved in all three sinter plant as shown in Fig. 21.

Thus, universal effect of RF-BEBIOS on productivity has proved.

\section{Conclusions}

High permeability of sinter packed bed for sinter productivity improvement has achieved by RF-MEBIOS (Return Fine - Mosaic Embedding Iron Ore Sintering) process, in which dry return fine is added on granulated raw materials.

The high permeability increase is caused by two factors, which are low fine pseudo-particle size $(-0.25 \mathrm{~mm})$ ratio and low bulk density. The former is caused by granulation with high moisture content due to dry return fine addition after granulation. The latter is supposed to be caused by low friction between dry return fines and wet granulated.

These techniques have been applied in three sinter plants in Sumitomo Metal Industries, Ltd. and improvement of productivity has been confirmed in the all three plants.

\section{REFERENCES}

1) J. Sawamura, K. Itou, N. Uno and M. Oomizu: Tetsu-to-Hagané, 61 (1975), S416.

2) R. Nakajima, S. Komatsu, M. Shimizu, H. Inoue and A. Takagi: Tetsu-to-Hagané, 61 (1987), S765.

3) For example, S. Funada and T. Saito: Tetsu-to-Hagané, 43 (1957), 880 .

4) T. Kawaguchi, K. Kuriyama, S. Sato and K. Takada: Tetsu-toHagané, 76 (1990), 1642.

5) T. Haga, A. Ohshio, Y. Hida, H. Fukuda and N. Ogata: Tetsu-toHagané, 83 (1997), 233.

6) T. Matsumura, K. Miyagawa and Y. Yamagata: ISIJ Int., 45 (2005), 485.

7) E. Kasai, I. Shu, S. Kobayashi and Y. Omori: Tetsu-to-Hagané, 70 (1984), 520.

8) S. Suzuki, K. Sato and M. Fujimoto: Tetsu-to-Hagané, 73 (1987), 1932.

9) T. Kawaguchi: CAMP-ISIJ, 5 (1992), 129.

10) C. Kamijo, M. Matsumura and T. Kawaguchi: CAMP-ISIJ, 17 (2004), 120 .

11) T. Kawaguchi, C. Kamijo and M. Matsumura: Tetsu-to-Hagané, 92 (2006), 779.

12) T. Kawaguchi and T. Usui: ISIJ Int., 45 (2005), 414.

13) K. Tashiro, H. Soma, Y. Hosotani and N. Konno: Tetsu-to-Hagané, 63 (1977), S24.

14) E. Kasai, S. Komarov, K. Nushiro and M. Nakano: ISIJ Int., 45 (2005), 538.

15) C. Kamijo, M. Matsumura and T. Kawaguchi: ISIJ Int., 45 (2005), 544.

16) M. Matsumura and T. Kawaguchi: CAMP-ISIJ, 20 (2007), 72.

17) T. Kawaguchi and M. Matsumura: CAMP-ISIJ, 21 (2008), 55, CDROM.

18) Y. Yamaguchi, C. Kamijo and T. Kawaguchi: CAMP-ISIJ, 24 (2011), 195, CD-ROM. 